\begin{abstract}
The phenomenon of multiple brooding, the production of more than one brood within a reproductive season, is a poorly understood process in rockfishes (Sebastes spp.). Most species produce a single brood, and all stock assessment models for Sebastes species assume the reproductive output (fecundity) of a single annual brood. We evaluated how well this life history trait could be predicted by both oceanographic (mean latitude, ocean temperature, dissolved oxygen levels, and depth) and demographic (maximum length, maximum age, and natural mortality rate) factors for 24 species of rockfish found on the continental shelf along the West Coast of the United States. Our results indicate that multiple-brooding species are considerably more common in lower latitudes $\left(32-36^{\circ} \mathrm{N}\right)$ or in warmer waters $\left(>9^{\circ} \mathrm{C}\right.$ at depth) and that the other environmental and demographic factors analyzed were not empirically informative. This work provides a more comprehensive understanding of the reproductive ecology of shelf rockfishes, could contribute to assessments of climate change vulnerability, and should eventually lead to improvements in stock assessment models for economically and ecologically important rockfishes.
\end{abstract}

Manuscript submitted 20 October 2018. Manuscript accepted 19 July 2019. Fish. Bull. 117:180-188 (2019). Online publication date: 31 July 2019. doi: 10.7755/FB.117.3.5

The views and opinions expressed or implied in this article are those of the author (or authors) and do not necessarily reflect the position of the National Marine Fisheries Service, NOAA.

\title{
An exploration of factors that relate to the occurrence of multiple brooding in rockfishes (Sebastes spp.)
}

\author{
Anna M. Holder (contact author) ${ }^{1}$ \\ John C. Field ${ }^{2}$ \\ Email address for contact author: aholder@csumb.edu \\ ${ }^{1}$ California State University, Monterey Bay \\ 100 Campus Center \\ Seaside, California 93955 \\ ${ }^{2}$ Fisheries Ecology Division \\ Southwest Fisheries Science Center \\ National Marine Fisheries Service, NOAA \\ 110 Shaffer Road \\ Santa Cruz, California 95060
}

Population dynamics models that inform management decisions require an understanding of the reproductive biology of the fish species that are being managed. Rockfishes (Sebastes spp.) of the northeast Pacific Ocean tend to be long-lived species (maximum ages of some species are between 50 and 150 years) that can reach marketable size before maturity (Love et al., 1990). In addition to being long lived, slow growing, and late to mature, they have internal fertilization, are live-bearing, and usually develop a single brood annually (Love et al., 2002). Given these traits, which tend to be associated with high standing stock biomass and low productivity, rockfishes tend to be among the stocks that are more vulnerable to fishing pressure and presumably to future climate change (Parker et al., 2000; Berkeley et al., 2004; Cope et al., 2011).

Despite the report of multiple brooding, the production of more than one brood within a reproductive season, in some rockfishes over 50 years ago (Moser, 1966), multiple brooding continues to be poorly understood. Multiple brooding can be identified through macroscopic or histological examination of the ovaries. In macroscopically examined ovaries, multiple broods can be identified when ovaries contain residual larvae or fertilized eggs (primary brood) and developing oocytes (upcoming secondary brood) (Beyer et al., 2015; Lefebvre et al., 2018). Lefebvre et al. (2018) identified multiple brooding through histological examination when ovaries contained postovulatory follicle complexes, residual larvae or eyed larvae (primary brood) and late-stage developing vitellogenic oocytes (upcoming secondary brood). Although many rockfish species have been identified as having the capacity to produce multiple broods (Moser, 1967; Love et al., 1990; Beyer et al., 2015; Lefebvre et al., 2018), the potential for multiple brooding is unknown for a great many remaining species for which little data on their reproductive ecology exists.

Traditional stock assessment metrics, such as estimates of spawning stock biomass, depend on the reproductive strategies and annual fecundity of species. When data are not available, assumptions are made that 
can result in bias and misspecification of stock status and associated parameters. For example, if size-dependent fecundity cannot be quantified in an assessment but such a relationship exists in a real population, assessment models will be biased toward estimating a stock status that is more optimistic than actually exists (He et al., 2015a; Barneche et al., 2018). There has been a growing awareness in recent years that the biological processes that determine a population's productivity are much more complicated than previously understood. For example, some Sebastes species exhibit skipped spawning (Rideout et al., 2005; Conrath, 2017), prolonged adolescent periods (Thompson and Hannah, 2010), and multiple brooding (Moser, 1967; Love et al., 1990; Beyer et al., 2015; Lefebvre et al., 2018). Accounting for all of these factors is critical in the understanding of a species' life history and in specifying life history characteristics in stock assessment models, climate vulnerability assessments, and other evaluations.

Previous studies indicate that multiple brooding more commonly occurs in southerly distributed rockfish species $\left(32-36^{\circ} \mathrm{N}\right)$, as well as in individuals residing in the southern extent of the range of their species (Love et al., 1990; Beyer et al., 2015). For example, bocaccio (S. paucispinis) range from the Southern California Bight to British Columbia, Canada; individuals in the Southern California Bight frequently exhibit multiple brooding and those in Central California occasionally exhibit multiple brooding, but the phenomenon has never been reported in individuals north of Cape Mendocino (He et al., 2015b). Multiple brooding has not been reported in northern stocks (Love et al., 2002; Conrath, 2017), nor in species typically found in deeper water (on the continental slope at depths $>400 \mathrm{~m}$ ), other than the bank rockfish (S. rufus) in Southern California. However, beyond these general observations, the phenomenon of multiple brooding has never been empirically evaluated in relation to environmental or life history factors, and we have yet to determine if multiple brooding can be robustly predicted on a species level to allow estimation of the implications to stock assessments and climate vulnerability assessments.

We sought to quantitatively document the relationship between the phenomenon of multiple brooding in West Coast rockfishes with latitude or other demographic (maximum length, maximum age, and natural mortality rate) and environmental (temperature and dissolved oxygen [DO] at depth, and average depth) factors and to determine which of these factors would be the best predictors of multiple brooding. Specifically, we hypothesized that rockfish species of the continental shelf of the West Coast of the United States that are able to produce multiple broods would be statistically more likely to inhabit lower latitudes $\left(32-36^{\circ} \mathrm{N}\right)$ or warmer waters $\left(>9^{\circ} \mathrm{C}\right.$ at depth). The results of this research are intended to provide a more comprehensive understanding of the reproductive biology of rockfish species and to improve the information available for their sustainable management.

\section{Materials and methods}

\section{Study area and data collection}

Researchers at the Fisheries Ecology Division of the NOAA Southwest Fisheries Science Center have been collecting fecundity samples of a range of rockfishes to improve our understanding of size-dependent fecundity and carefully noting the presence or absence of multiple broods (Beyer et al., 2015; Lefebvre et al., 2018). On the basis of these efforts and previous reports (Moser, 1966, 1967; MacGregor, 1970; Wyllie Echeverria, 1987; Love et al., 1990; Ralston and MacFarlane, 2010), we classified 13 rockfish species found on the continental shelf of the West Coast as being multiple brooders and 11 shelf rockfish species as single brooders ( $n=24$; Table 1 ).

The NOAA Northwest Fisheries Science Center has conducted a fishery-independent groundfish bottomtrawl survey along the U.S. West Coast annually since 2003, in an area extending from the U.S.-Mexico border (latitude $32^{\circ} 30^{\prime} \mathrm{N}$ ) to the U.S.-Canada border (latitude $48^{\circ} 10^{\prime} \mathrm{N}$ ) and including depths from $55 \mathrm{~m}$ to $1280 \mathrm{~m}$ (Keller et al., 2012). We downloaded physical (trawl location, temperature, DO concentration at depth, and trawl depth) and biological (species and sex) data for shelf rockfishes (as defined in PFMC, 2016) for trawl tows conducted from 2004 through 2015 (FRAM Data Warehouse, Northwest Fisheries Science Center, available from website). It is important to note that the DO concentration at depth was not collected until 2007 and was not collected consistently until 2010. We downloaded commercial landings over the same time period from the Pacific Fisheries Information Network (PacFIN, available from website) and assigned port code latitudes based on port locations. We acquired the maximum length (i.e., asymptotic average fork length in centimeters; see Francis, 1988), maximum age (in years), and natural mortality rate of the species of interest from published stock assessments by the Pacific Fishery Management Council (available from website), Dick and MacCall (2010), and Love et al. (2002) (Table 1). Estimates of the natural mortality rate for shortbelly rockfish (Sebastes jordani) were used for halfbanded and pygmy rockfishes (S. semicinctus and $S$. wilsoni, respectively) because natural mortality had not been estimated for those 2 species and all 3 species are small, rapidly growing dwarf species. Species were excluded from our analyses if fewer than 20 individuals were collected over all the trawl samples; trawl samples were excluded if the tow of the trawl was conducted deeper than the depth range of continental shelf habitat (depths $>400 \mathrm{~m}$ ).

\section{Data analysis}

To provide some context to our analyses, we explored how cumulative survey and commercial catch (measured as weight in kilograms) varied by latitude for each species by plotting the cumulative distribution of the survey and commercial catch data, and the arithmetic mean 


\section{Table 1}

Multiple brooder classification (MB; $\mathrm{Y}=\mathrm{yes}, \mathrm{N}=$ no), mean latitude (in decimal degrees), maximum fork length $\left(L_{\infty}, \mathrm{cm}\right)$, observed maximum age $\left(A_{\mathrm{MAX}}\right.$, years), and natural mortality rate $(M)$ for each species of rockfish (Sebastes spp.) collected by the Pacific Fishery Management Council and NOAA Southwest Fishery Science Center between 2004 and 2015 on the continental shelf along the West Coast of the United States. For species for which parameters varied by sex, values for females are given.

\begin{tabular}{|c|c|c|c|c|c|c|}
\hline Common name & Scientific name & $\mathrm{MB}$ & Mean latitude & $L_{\infty}$ & $A_{\mathrm{MAX}}$ & $M$ \\
\hline Bocaccio & Sebastes paucispinis & $\mathrm{Y}$ & 35.87 & 75.90 & 37 & 0.15 \\
\hline Canary & Sebastes pinniger & $\mathrm{N}$ & 44.78 & 62.00 & 84 & 0.05 \\
\hline Chilipepper & Sebastes goodei & $\mathrm{Y}$ & 37.82 & 52.00 & 35 & 0.16 \\
\hline Cowcod & Sebastes levis & $\mathrm{Y}$ & 35.50 & 87.00 & 55 & 0.06 \\
\hline Flag & Sebastes rubrivinctus & $\mathrm{N}$ & 34.24 & 51.00 & 38 & 0.12 \\
\hline Greenblotched & Sebastes rosenblatti & $\mathrm{Y}$ & 34.06 & 57.99 & 50 & 0.09 \\
\hline Greenspotted & Sebastes chlorostictus & $\mathrm{Y}$ & 36.53 & 44.20 & 51 & 0.09 \\
\hline Greenstriped & Sebastes elongatus & $\mathrm{Y}$ & 42.86 & 37.26 & 54 & 0.08 \\
\hline Halfbanded & Sebastes semicinctus & $\mathrm{N}$ & 34.57 & 18.14 & 15 & 0.26 \\
\hline Pink & Sebastes eos & $\mathrm{Y}$ & 34.00 & 56.00 & 66 & 0.07 \\
\hline Pygmy & Sebastes wilsoni & $\mathrm{N}$ & 42.67 & 23.00 & 26 & 0.26 \\
\hline Redstripe & Sebastes proriger & $\mathrm{N}$ & 45.53 & 61.00 & 55 & 0.08 \\
\hline Rosethorn & Sebastes helvomaculatus & $\mathrm{N}$ & 43.78 & 28.66 & 87 & 0.05 \\
\hline Rosy & Sebastes rosaceus & $\mathrm{Y}$ & 33.87 & 32.90 & 18 & 0.27 \\
\hline Shortbelly & Sebastes jordani & $\mathrm{Y}$ & 36.00 & 28.50 & 32 & 0.26 \\
\hline Silvergray & Sebastes brevispinis & $\mathrm{N}$ & 45.78 & 71.00 & 82 & 0.05 \\
\hline Speckled & Sebastes ovalis & $\mathrm{Y}$ & 33.67 & 49.99 & 37 & 0.13 \\
\hline Squarespot & Sebastes hopkinsi & $\mathrm{Y}$ & 34.82 & 25.25 & 19 & 0.26 \\
\hline Starry & Sebastes constellatus & $\mathrm{Y}$ & 35.64 & 45.00 & 32 & 0.15 \\
\hline Stripetail & Sebastes saxicola & $\mathrm{N}$ & 38.30 & 33.05 & 38 & 0.12 \\
\hline Swordspine & Sebastes ensifer & $\mathrm{Y}$ & 33.76 & 17.60 & 43 & 0.11 \\
\hline Vermilion & Sebastes miniatus & $\mathrm{N}$ & 34.73 & 62.40 & 60 & 0.07 \\
\hline Widow & Sebastes entomelas & $\mathrm{N}$ & 42.90 & 50.34 & 60 & 0.08 \\
\hline Yellowtail & Sebastes flavidus & $\mathrm{N}$ & 46.37 & 52.20 & 64 & 0.15 \\
\hline
\end{tabular}

of both data sources, for each species. We then pooled data from the respective data sets over the study period (2004-2015) and summarized them by calculating the arithmetic mean to provide estimates of mean latitude (in decimal degrees), mean temperature at depth (in degrees Celsius), mean DO concentration at depth (in milliliters per liter), mean survey depth (in meters) for each species in the study ( $n=1$, for each species). We fit binomial generalized linear models to the probability of each species being identified as a multiple brooder. The capacity to produce multiple broods was the response variable, and the environmental and demographic metrics were predictor variables.

Because temperature and latitude were likely highly correlated, we analyzed the collinearity between all explanatory variables using scatterplots and conducted a variance inflation factor (VIF) analysis. In the VIF analysis, we used an a priori cutoff of 10 (Craney and Surles, 2002) to assess whether collinearity between the variables was problematic. If variables had a VIF greater than 10, they were not used in the same model. Using the results of the VIF analysis, we created 23 candidate models that represented hypothesized potential predictor-response relationships. We compared models using an information-theoretic approach using Akaike information criterion corrected for small sample sizes $\left(\mathrm{AIC}_{\mathrm{c}}\right.$ ) (Burnham and Anderson, 2002). Following the general method used by Kowalski et al. (2015), we computed the maximized log-likelihood, AIC and $\mathrm{AIC}_{\mathrm{c}}$ scores, $\Delta \mathrm{AIC}_{\mathrm{c}}$ values (difference between the $\mathrm{AIC}_{\mathrm{c}}$ of model $i$ and the smallest $\mathrm{AIC}_{\mathrm{c}}$ among the considered models), and the $\mathrm{AIC}$ weight $\left(\mathrm{AIC}_{\mathrm{w}}\right)$ for each model. A priori, we decided to describe the level of empirical support for a model using the terms substantial, considerably less, and essentially none to correspond to $\Delta \mathrm{AIC}_{\mathrm{c}}$ values less than 2 , between 4-7, and greater than 10, respectively (as advised by Burnham and Anderson, 2002).

We evaluated the relative importance of influence of each predictor by summing the product of $\mathrm{AIC}_{\mathrm{w}}$ and frequency of occurrence of the variable for all models. We computed the log evidence ratio (LER) in support for each predictor by calculating the $\log _{10}$ of its evidence ratio (quotient of relative importance and its complement) and used LERs as the basis of inference for predictor comparisons. Following Kass and Raftery (1995), a priori, we decided to use the terms minimal, substantial, strong, and decisive to correspond approximately to LERs greater than $0,0.5,1$, and 2 , respectively. All analyses were executed by using $\mathrm{R}$ statistical software (vers. 3.4.4; R Core Team, 2018), including the glm, AIC, and ggplot functions of this software. 


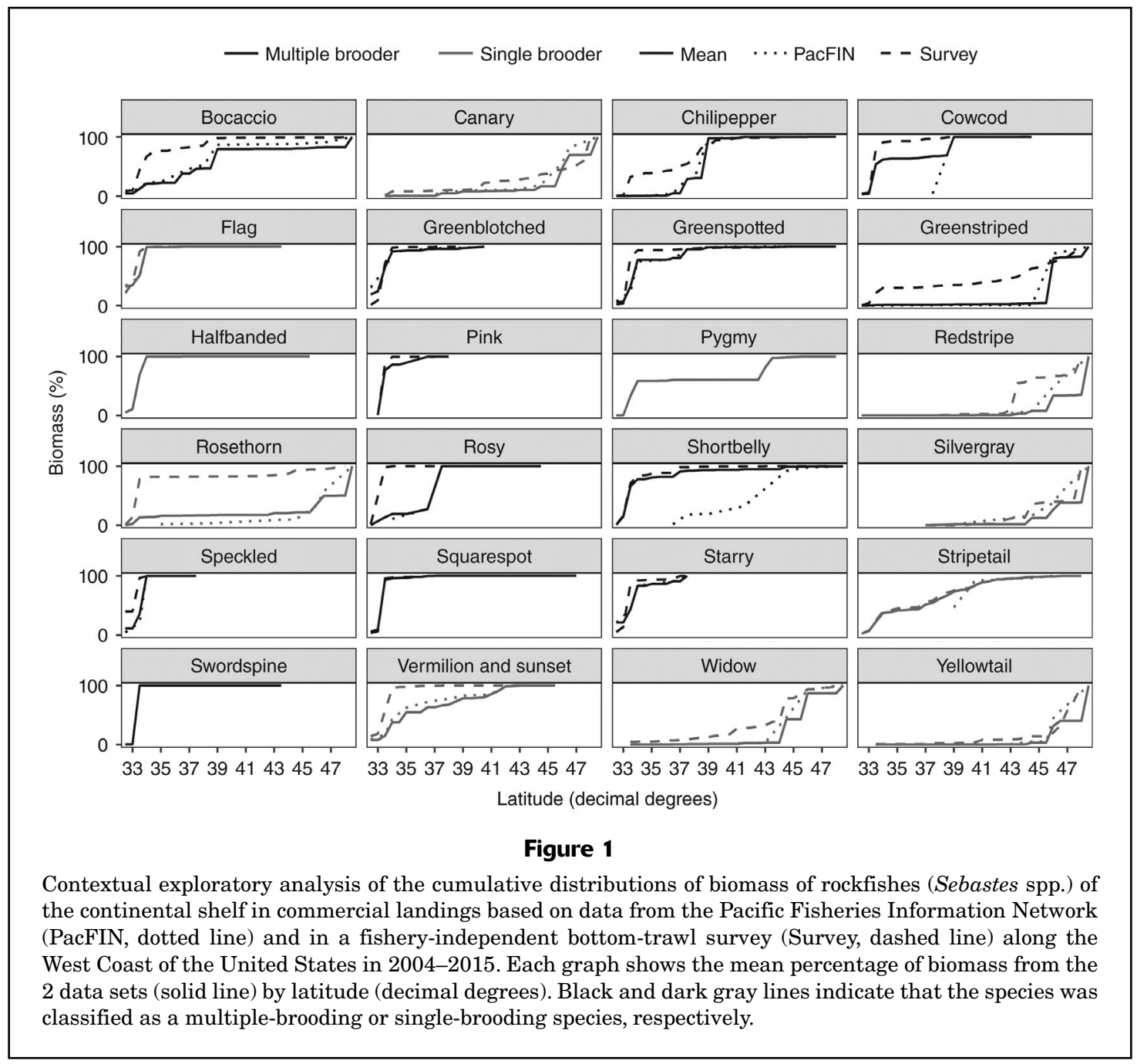

\section{Results}

The results of exploratory analysis of the cumulative distribution of all rockfishes of the continental shelf that were present in the trawl survey's catch data reveal distinct differences in latitude between single- and multiple-brooding species and similar trends between commercial and survey data (Fig. 1). There appears to have been substantial differences in both latitude and temperature between single and multiple-brooding species and slight differences in DO, depth, and all demographic variables between singlebrooding and multiple-brooding species (Table 2).

Unsurprisingly, latitude and temperature were highly correlated (VIFs: 71 and 67, respectively). To address multicollinearity issues, latitude and temperature were included in separate models before retesting all VIF scores, and they remained separate in the rest of the models. Of the 23 models considered, we found substantial support for those models that included latitude and found considerably less support for models that included temperature: (model 1 [M1]: $\Delta \mathrm{AIC}_{\mathrm{c}}=0.0$; model 2 [M2]: $\Delta \mathrm{AIC}_{\mathrm{c}}=0.7$; and model 4 [M4]: $\Delta \mathrm{AIC}_{\mathrm{c}}=3.2$; Table 3). There was marginal support for models that included some demographic variables (model 3 [M3]: $\Delta \mathrm{AIC}_{\mathrm{c}}=2.7$; Table 3 ). The poorest performing models had essentially no support and were those for which latitude and temperature were separate (as required by the VIF results) but included all other variables (model containing all variables except temperature: $\Delta \mathrm{AIC}_{\mathrm{c}}=11.6$; model containing all variables except latitude: $\Delta \mathrm{AIC}_{\mathrm{c}}=14.1$; not shown).

Latitude and temperature were the strongest predictors of whether a shelf rockfish species could be a multiple brooder. There was substantial support for M1, which contained latitude and DO, and for M2, which contained only latitude, and there was considerably less support for M4 and M5, both of which include temperature (Table 3). When comparing the coefficients of M1 and M4, which contain DO and latitude (M1) or temperature (M4), the estimate for the latitude coefficient indicates that when DO is fixed and latitude increases by $1^{\circ}$, the odds of a shelf rockfish species being a multiple brooder is 0.6 times that of being a single brooder (for coefficients, see Table 3). Correspondingly, 
Table 2

Comparison of the arithmetic mean and standard deviation (SD) of environmental and demographic variables between single- and multiple-brooding rockfish species (Sebastes spp.): latitude (decimal degrees), temperature $\left({ }^{\circ} \mathrm{C}\right)$, dissolved oxygen $(\mathrm{DO})$ concentration $(\mathrm{mL} / \mathrm{L})$, depth $(\mathrm{m})$, maximum fork length $\left(L_{\infty}, \mathrm{cm}\right)$, observed maximum age $\left(A_{\mathrm{MAX}}\right.$, years), and natural mortality rate $(M)$. Data are provided for fish collected along the West Coast of the United States.

\begin{tabular}{lrrrrr}
\hline & \multicolumn{2}{c}{ Single brooding } & & \multicolumn{2}{c}{ Multiple brooding } \\
\cline { 2 - 3 } Variable & Mean & SD & & Mean & SD \\
\hline Latitude & 41.24 & 4.83 & & 35.72 & 2.49 \\
Temperature & 8.11 & 1.29 & & 9.09 & 0.50 \\
DO & 1.94 & 0.44 & & 1.91 & 0.46 \\
Depth & 157.44 & 28.18 & & 161.35 & 34.33 \\
$L_{\infty}$ & 46.62 & 17.96 & & 46.89 & 19.70 \\
$A_{\text {MAX }}$ & 55.36 & 23.96 & & 40.69 & 14.19 \\
$M$ & 0.12 & 0.08 & & 0.14 & 0.08 \\
& & & & \\
\hline
\end{tabular}

\begin{tabular}{|c|c|c|c|c|c|c|c|}
\hline \multicolumn{8}{|c|}{ Table 3} \\
\hline \multicolumn{8}{|c|}{ 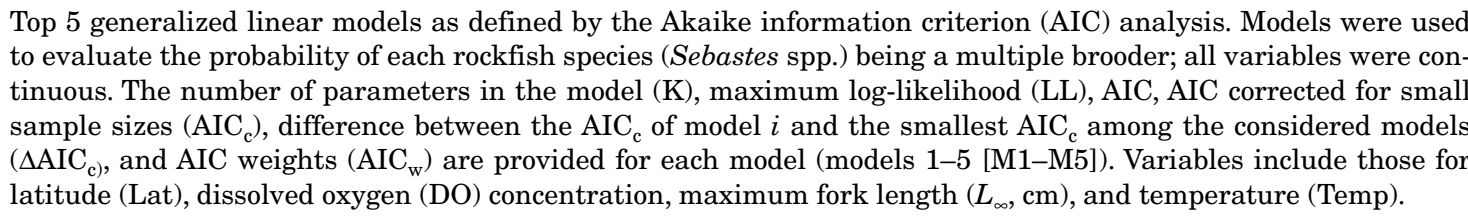 } \\
\hline Model name & Model $(\log (\hat{y})=)$ & $\mathrm{K}$ & LL & AIC & $\mathrm{AIC}_{\mathrm{c}}$ & $\Delta \mathrm{AIC}_{\mathrm{c}}$ & $\mathrm{AIC}_{\mathrm{w}}$ \\
\hline M1 & $25.27-0.51 X_{\text {Lat }}-2.78 X_{\mathrm{DO}}$ & 3 & -9.95 & 25.91 & 27.11 & 0.00 & 0.39 \\
\hline M2 & $13.32-0.35 X_{\text {Lat }}$ & 2 & -11.61 & 27.22 & 27.79 & 0.68 & 0.28 \\
\hline M3 & $25.14-0.52 X_{\text {Lat }}-2.85 X_{\mathrm{DO}}+0.01 X_{\mathrm{L}_{\infty}}$ & 4 & -9.87 & 27.73 & 29.84 & 2.73 & 0.10 \\
\hline M4 & $-10.55+1.98 X_{\mathrm{Temp}}-3.25 X_{\mathrm{DO}}$ & 3 & -11.54 & 29.07 & 30.27 & 3.16 & 0.08 \\
\hline M5 & $-9.02+1.06 X_{\text {Temp }}$ & 2 & -13.68 & 31.36 & 31.93 & 4.82 & 0.04 \\
\hline
\end{tabular}

the estimate for the temperature coefficient indicates that when $\mathrm{DO}$ is fixed and temperature increases by $1^{\circ} \mathrm{C}$, the odds of a shelf rockfish species being a multiple brooder is 7.2 times that of being a single brooder. Finally, the results of evaluation of relative importance of influence of each predictor indicate that there was substantial evidence that species in lower latitudes had a higher probability of being a multiple brooder (LER for latitude $=0.63$; Table 4). There was minimal evidence indicating that any of the other variables affected the probability of a species being a multiple brooder (all other LERs were <0.5; Table 4).

\section{Discussion}

Our results indicate that species with the capacity for multiple brooding were more likely to occur in lower latitudes $\left(32-36^{\circ} \mathrm{N}\right)$ or in warmer waters $\left(>9^{\circ} \mathrm{C}\right.$ at depth).
This finding agrees with the established knowledge on differing distributions and community assemblages of rockfishes regionally (e.g., by latitude) (Love et al., 2002; Williams and Ralston, 2002; Gunderson and Vetter, 2006). Oceanographic conditions in waters of Southern California and Central California are characterized by warmer conditions and more variable, less seasonal upwelling patterns relative to conditions in the northern part of the California Current (e.g., north of Cape Mendocino), where ocean temperatures tend to be cooler and upwelling is both stronger and more strongly seasonal, conditions that result in higher primary and secondary productivity (Parrish et al., 1981; Ware and Thomson, 2005; Checkley and Barth, 2009). Consequently, rockfish species in waters of Southern California, where primary and secondary productivity and therefore presumably forage availability are both lower and characterized by greater interannual variability, may have an 


\section{Table 4}

Summary of predictor variables considered in generalized linear models used to evaluate the probability of a rockfish species (Sebastes spp.) being a multiple brooder. Predictor variables include latitude (decimal degrees), temperature $\left({ }^{\circ} \mathrm{C}\right)$, dissolved oxygen (DO) concentration $(\mathrm{mL} / \mathrm{L})$, depth $(\mathrm{m})$, maximum fork length $\left(L_{\infty}, \mathrm{cm}\right)$, maximum age $\left(A_{\mathrm{MAX}}\right.$, years), and natural mortality rate $(M)$. Relative importance (RI), evidence ratio (ER), log evidence ratio (LER), and direction of effect (Direction) on the probability of a species being a multiple brooder for each predictor are shown.

\begin{tabular}{lcccc}
\hline Predictor variable & RI & ER & LER & Direction \\
\hline Latitude & 0.81 & 4.27 & 0.63 & - \\
DO & 0.64 & 1.79 & 0.25 & - \\
$L_{\infty}$ & 0.18 & 0.21 & -0.67 & + \\
Temperature & 0.15 & 0.17 & -0.76 & + \\
$A_{\text {MAX }}$ & 0.07 & 0.08 & -1.10 & + \\
$M$ & 0.03 & 0.03 & -1.58 & + \\
Depth & 0.01 & 0.01 & -2.19 & \\
& & & & \\
\hline
\end{tabular}

evolutionary advantage in producing multiple broods over those species constrained to a single brood. The presumed mechanism for such an advantage would be to increase the probability of post-parturition larvae to encounter appropriate foraging conditions in this more variable, less seasonal region of the California Current. This is consistent with the notion of Cushing's matchmismatch hypothesis in which the effect of highly variable prey abundance for early life history stages of marine fish species may be partially mitigated by spreading spawning effort across a broader time period (Cushing, 1990).

Temperature affects individuals directly by influencing their growth and metabolism (Boehlert and Yoklavich, 1983; Boehlert et al., 1991). Temperature also influences egg and larval development; for example, recent laboratory studies have shown that multiple-brooding rosy rockfish (S. rosaceus) produced and released broods more quickly in warm water (relative to cool water) treatments, indicating faster development of eggs and larvae (Beyer ${ }^{1}$ ), and that faster development could result in the production of multiple broods during potentially narrow environmental windows for spawning. Temperature may tend to covary with other oceanographic variables that drive ocean productivity and consequently the availability of food resources, given that past studies have shown that the condition and reproductive output of some rockfish species can degrade during the warmer ocean conditions associated with El Niño-Southern Oscillation events (VenTresca et al., 1995; Harvey et al., 2011).

The importance of depth in this study is consistent with other studies that demonstrate that depth is a key driver of benthic community structure (Gunderson and Vetter, 2006; Tolimieri and Anderson, 2010). We did not include rockfish

\footnotetext{
${ }^{1}$ Beyer, S. 2018. Unpubl. data. Dep. Ecol. Evol. Biol., Univ. Calif. Santa Cruz., 130 McAllister Way, Santa Cruz, CA 95060.
}

species of the continental slope in this analysis because of our desire to focus on the multiple-brooding phenomenon, which is largely limited to species found on the continental shelf of the West Coast. However, we recognize that depth may more generally drive a broader range of reproductive strategies for rockfishes, such that species in deeper waters (>400 m) may respond to variable conditions by abortive maturity, skipped spawning, or atresia (Nichol and Pikitch, 1994; Lefebvre and Field, 2015; Conrath, 2017), rather than the production (or lack thereof) of multiple broods. Although we did not formally evaluate the phylogeny of rockfish species relative to the capacity to produce multiple broods, it would appear that there are examples of both single and multiple brooders across the phylogenetic range of the genus Sebastes (Hyde and Vetter, 2007).

The similar predictive ability of temperature and latitude reflects the prominence of the influence of these variables on current probability of shelf rockfish species being multiple brooders. However, ocean conditions are changing. As the effects of climate change become more pronounced, the environmental conditions that are associated with certain regions (i.e., latitudes) will also change. Additionally, we did not find any evidence indicating that demographic variables are substantially associated with the phenomenon of multiple brooding. Although the maximum length and maximum age of species did not serve as a substantial predictor of multiple brooding among species, within species the occurrence of multiple brooding has been shown to increase with both size and age (Beyer et al., 2015; Lefebvre et al., 2018). Our results are also relevant to consideration of how observations of multiple brooding within a stock or species may vary with future warming or with the increasingly variable ocean conditions expected, and potentially already being observed, as a result of climate change (Rykaczewski et al., 2015; McCabe et al., 2016). For example, Lefebvre et al. (2018) found that during 
atypically warm years, when upwelling and forage conditions were above average, the frequency of occurrence of multiple brooding in chilipepper ( $S$. goodei) was common and nearly equal in both Southern and Central California, whereas previous studies had not detected multiple broods in chilipepper of Central California (Wyllie Echeverria, 1987; Stafford et al., 2014). This finding might indicate that species capable of producing multiple broods do so more frequently under warmer ocean conditions when food resources are sufficient, potentially providing some advantage over single-brooding species in the face of warming trends.

Fisheries managers are beginning to prepare for the effects of climate change on fisheries by incorporating climate variables (such as ocean temperature trends) into harvest policies (Hill et al., 2017) and by conducting climate vulnerability assessments (Morrison et al., 2015; Hare et al., 2016). Climate vulnerability assessments evaluate which species will be at the greatest risk (or most vulnerable) to the effects of climate change, and these assessments consequently are intended to inform and prioritize research and management actions. Spawning frequency is 1 of 12 biological attributes used in the current criteria for evaluating vulnerability to climate change, with species that spawn in one single event per year considered to be more vulnerable than those that spawn several times per year (Hare et al., 2016). Therefore, multiple-brooding species may have an evolutionary advantage relative to single-brooding species in the face of either warming or more variable ocean conditions, necessitating an accurate assessment of the reproductive ecology of all Sebastes species in evaluating the vulnerability of different species to climate change.

Accounting for multiple brooding as a maternal effect in population models can substantially affect stock assessments, particularly if the likelihood of producing multiple broods (increasing overall reproductive output) is size dependent, as demonstrated for chilipepper (Lefebvre et al., 2018). Currently, stock assessment models of multiple-brooding species do not account for such factors in estimating reproductive output and stock status, potentially biasing assessment results if the effect is to nominally increase reproductive output of larger, older individuals. Taking multiple brooding into account in general, as well as in the context of climate change, will improve stock assessments and help managers develop appropriate management responses to climate variability and change now and into the future (Barneche et al., 2018). Our results provide robust predictions of this likelihood and provide context to the observed distribution of multiple-brooding species relative to single-brooding shelf rockfish species. However, our insights are not strictly mechanistic and are only the first step toward understanding the mechanisms and evolution of multiple brooding in rockfish species of the continental shelf. Future research should explicitly explore the mechanisms that drive multiple versus single brooding to aid in closing the knowledge gap for multiple-brooding rockfish species.

\section{Acknowledgments}

We would like to thank S. Sogard, S. Beyer, L. Lefebvre, N. Kashef, and D. Stafford at the Fisheries Ecology Division of the Southwest Fisheries Science Center and the University of California's Cooperative Institute for Marine Ecosystems and Climate because their combined efforts were critical to inform and guide this effort. Additionally, we are deeply appreciative of the detailed comments provided by 3 anonymous reviewers and feel that incorporating their recommendations has greatly improved this manuscript.

\section{Literature cited}

Barneche, D. R., D. R. Robertson, C. R. White, and D. J. Marshall. 2018. Fish reproductive-energy output increases disproportionately with body size. Science 360:642-645. Crossref

Berkeley, S. A., M. A. Hixon, R. J. Larson, and M. S. Love. 2004. Fisheries sustainability via protection of age structure and spatial distribution of fish populations. Fisheries 29:23-32. Crossref

Beyer, S. G., S. M. Sogard, C. J. Harvey, and J. C. Field.

2015. Variability in rockfish (Sebastes spp.) fecundity: species contrasts, maternal size effects, and spatial differences. Environ. Biol. Fish. 98:81-100. Crossref

Boehlert, G. W., and M. M. Yoklavich.

1983. Effects of temperature, ration, and fish size on growth of juvenile black rockfish, Sebastes melanops. Environ. Biol. Fish. 8:17-28. Crossref

Boehlert, G. W., M. Kusakari, and J. Yamada.

1991. Oxygen consumption of gestating female Sebastes schlegeli: estimating the reproductive costs of livebearing. Environ. Biol. Fish. 30:81-90. Crossref

Burnham, K. P., and D. R. Anderson.

2002. Model selection and multimodel inference: a practical information theoretic approach, $2^{\text {nd }}$ ed., 488 p. Springer, New York.

Checkley, D. M., and J. A. Barth.

2009. Patterns and processes in the California Current System. Prog. Oceanogr. 83:49-64. Crossref

Conrath, C. L.

2017. Maturity, spawning omission, and reproductive complexity of deepwater rockfish. Trans. Am. Fish. Soc. 146:495-507. Crossref

Cope, J. M., J. DeVore, E. J. Dick, K. Ames, J. Budrick, D. L. Erickson, J. Grebel, G. Hanshew, R. Jones, L. Mattes, et al.

2011. An approach to defining stock complexes for US West Coast groundfishes using vulnerabilities and ecological distributions. N. Am. J. Fish. Manage. 31:589-604. Crossref

Craney, T. A., and J. G. Surles.

2002. Model-dependent variance inflation factor cutoff values. Qual. Eng. 14:391-403. Crossref

Cushing, D. H.

1990. Plankton production and year-class strength in fish populations: an update of the match/mismatch hypothesis. Adv. Mar. Biol. 26:249-293. Crossref

Dick, E. J., and A. D. MacCall.

2010. Estimates of sustainable yield for 50 data-poor stocks in the Pacific Coast groundfish fishery management plan. NOAA Tech. Memo. NMFS-SWFSC460, $208 \mathrm{p}$. 
Francis, R. I. C. C.

1988. Are growth parameters estimated from tagging and age-length data comparable? Can. J. Fish. Aquat. Sci. 45:936-942. Crossref

Gunderson, D. R., and R. D. Vetter.

2006. Temperate rocky reef fishes. In Marine metapopulations (J. P. Kritzer and P. F. Sale, eds.), p. 69-118. Elsevier, San Diego, CA.

Hare, J. A., W. E. Morrison, M. W. Nelson, M. M. Stachura, E. J. Teeters, R. B. Griffis, M. A. Alexander, J. D. Scott, L. Alade, R. J. Bell, et al.

2016. A vulnerability assessment of fish and invertebrates to climate change on the Northeast U.S. continental shelf. PLoS ONE 11(2):e0146756. Crossref

Harvey, C. J., J. C. Field, S. G. Beyer, and S. M. Sogard.

2011. Modeling growth and reproduction of chilipepper rockfish under variable environmental conditions. Fish. Res. 109:187-200. Crossref

He, X., J. C. Field, S. G. Beyer, and S. M. Sogard.

2015a. Effects of size-dependent relative fecundity specifications in fishery stock assessments. Fish. Res. 165:54-62. Crossref

He, X., J. C. Field, D. E. Pearson, L. Lefebvre, and S. Lindley.

2015b. Status of bocaccio, Sebastes paucispinis, in the Conception, Monterey and Eureka INPFC areas for 2015. Pacific Fishery Management Council stock assessment and fishery evaluation. Pac. Fish. Manage. Counc., Portland, OR. [Available from website.]

Hill, K. T., P. R. Crone, and J. P. Zwolinski.

2017. Assessment of the Pacific sardine resource in 2017 for U.S. management in 2017-18. NOAA Tech. Memo. NMFSSWFSC-576, $262 \mathrm{p}$.

Hyde, J. R., and R. D. Vetter.

2007. The origin, evolution, and diversification of rockfishes of the genus Sebastes (Cuvier). Mol. Phylogenet. Evol. 44:790-811. Crossref

Kass, R. E., and A. E. Raftery. 1995. Bayes factors. J. Am. Stat. Assoc. 90:773-795. Crossref

Keller, A., J. R. Wallace, B. H. Horness, O. S. Hamel, and I. J. Stewart. 2012. Variations in eastern North Pacific demersal fish biomass based on the U.S. west coast groundfish bottom trawl survey (2003-2010). Fish. Bull. 110:63-80.

Kowalski, B., F. Watson, C. Garza, and B. Delgado.

2015. Effects of landscape covariates on the distribution and detection probabilities of mammalian carnivores. J. Mamm. 96:511-521. Crossref

Lefebvre, L. S., and J. C. Field.

2015. Reproductive complexity in a long-lived deepwater fish, the blackgill rockfish. Trans. Am. Fish. Soc. 144:383-399. Crossref

Lefebvre, L. S., S. G. Beyer, D. M. Stafford, N. S. Kashef, E. J. Dick,

S. M. Sogard, and J. C. Field.

2018. Double or nothing: plasticity in reproductive output in the chilipepper rockfish (Sebastes goodei). Fish. Res. 204:258-268. Crossref

Love, M. S., P. Morris, M. McCrae, and R. Collins. 1990. Life history aspects of 19 rockfish species (Scorpaenidae: Sebastes) from the southern California Bight. NOAA Tech. Rep. NMFS 87, $44 \mathrm{p}$.

Love, M. S., M. Yoklavich, and L. Thorsteinson. 2002. The rockfishes of the Northeast Pacific, 416 p. Univ. Calif. Press, Berkeley, CA.

MacGregor, J. S.

1970. Fecundity, multiple spawning, and description of the gonads in Sebastodes. U.S. Fish Wildl. Serv., Spec. Sci. Rep. Fish. 596, 12 p.
McCabe, R. M., B. M. Hickey, R. M. Kudela, K. A. Lefebvre, N. G. Adams, B. D. Bill, F. M. Gulland, R. E. Thomson, W. P. Cochlan, and V. L. Trainer.

2016. An unprecedented coastwide toxic algal bloom linked to anomalous ocean conditions. Geophys. Res. Lett. 43:10366. Crossref

Morrison W. E., M. W. Nelson, J. F. Howard, E. J. Teeters, J. A. Hare, R. B. Griffis, J. D. Scott, and M. A. Alexander.

2015. Methodology for assessing the vulnerability of marine fish and shellfish species to a changing climate. NOAA Tech. Memo. NMFS-OSF-3, 48 p.

Moser, H. G.

1966. Reproductive and developmental biology of the rockfishes (Sebastodes spp.) off California Ph.D. diss., 561 p. Univ. South. Calif., Los Angeles, CA.

1967. Reproduction and development of Sebastodes paucispinis and comparison with other rockfishes off southern California. Copeia 1967:773-797. Crossref

Nichol, D. G., and E. K. Pikitch.

1994. Reproduction of darkblotched rockfish off the OregonCoast. Trans. Am. Fish. Soc. 123:469-481. Crossref

PFMC (Pacific Fishery Management Council).

2016. Status of the Pacific coast groundfish fishery: stock assessment and fishery evaluation, 309 p. Pac. Fish. Manage. Counc., Portland, OR 97220. [Available from website.]

Parker, S. J., S. A. Berkeley, J. T. Golden, D. R. Gunderson, J. Heifetz, M. A. Hixon, R. Larson, B. M. Leaman, M. S. Love,

J. A. Musick, et al.

2000. Management of Pacific rockfish. Fisheries 25:22-30. Crossref

Parrish, R. H., C. S. Nelson, and A. Bakun.

1981. Transport mechanisms and reproductive success of fishes in the California Current. Biol. Oceanogr. $1: 175-203$

$\mathrm{R}$ Core Team.

2018. R: a language and environment for statistical computing. R Foundation for Statistical Computing, Vienna, Austria. [Available from website, accessed April 2018.]

Ralston, S., and B. R. MacFarlane.

2010. Population estimation of bocaccio (Sebastes paucispinis) based on larval production. Can. J. Fish. Aquat. Sci. 67:1005-1020. Crossref

Rideout, R. M., G. A. Rose, and M. P. M. Burton.

2005. Skipped spawning in female iteroparous fishes. Fish Fish. 6:50-72. Crossref

Rykaczewski, R. R., J. P. Dunne, W. J. Sydeman, M. García-Reyes, B. A. Black, and S. J. Bograd.

2015. Poleward displacement of coastal upwelling-favorable winds in the ocean's eastern boundary currents through the 21st century. Geophys. Res. Lett. 42:6424-6431. Crossref

Stafford, D. M., S. M. Sogard, and S. A. Berkeley.

2014. Maternal influence on timing of parturition, fecundity, and larval quality in three shelf rockfishes (Sebastes spp.). Aquat. Biol. 21:11-24. Crossref

Tolimieri, N., and M. J. Anderson.

2010. Taxonomic distinctness of demersal fishes of the California Current: moving beyond simple measures of diversity for marine ecosystem-based management. PLoS One 5:e10653. Crossref

Thompson, J. E., and R. W. Hannah.

2010. Using cross-dating techniques to validate ages of aurora rockfish (Sebastes aurora): estimates of age, growth and female maturity. Environ. Biol. Fish. 88:377388. Crossref 
VenTresca, D. A., R. H. Parrish, J. L. Houk, M. L. Gingras, S. D. Short, and N. L. Crane.

1995. El Niño effects on the somatic and reproductive condition of blue rockfish, Sebastes mystinus. CalCOFI Rep. 36:167-174.

Ware, D. M., and R. E. Thomson.

2005. Bottom-up ecosystem trophic dynamics determine fish production in the Northeast Pacific. Science 308:1280 1284. Crossref
Williams, E. H., and S. Ralston.

2002. Distribution and co-occurrence of rockfishes (family: Sebastidae) over trawlable shelf and slope habitats of California and southern Oregon. Fish. Bull. 100:836-855.

Wyllie Echeverria, $\mathrm{T}$.

1987. Thirty-four species of California rockfishes: maturity and seasonality of reproduction. Fish. Bull. 85:229-250. 